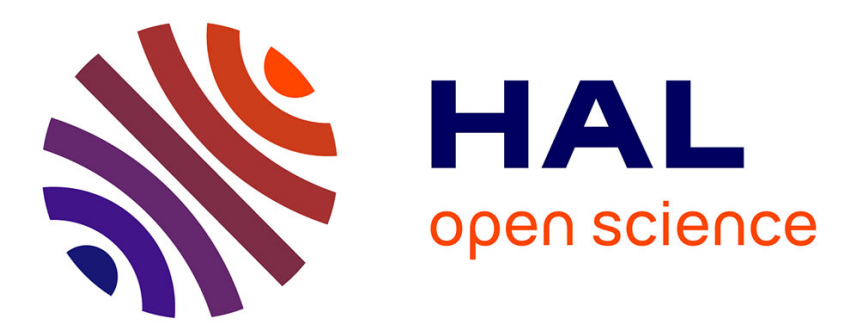

\title{
Novel interpenetrating polymer network composed of poly(butyl acrylates) and poly(ethyl-hexyl acrylate)
}

Kamel Eddine Boudraa, Tewfik Bouchaour, Christophe Beyens, Ulrich

Maschke

\section{- To cite this version:}

Kamel Eddine Boudraa, Tewfik Bouchaour, Christophe Beyens, Ulrich Maschke. Novel interpenetrating polymer network composed of poly(butyl acrylates) and poly(ethyl-hexyl acrylate). International Journal of Polymer Analysis and Characterization, 2020, International Journal of Polymer Analysis and Characterization, 25 (1), pp.18-33. 10.1080/1023666x.2020.1737467 . hal-03103016

\section{HAL Id: hal-03103016 \\ https://hal.univ-lille.fr/hal-03103016}

Submitted on 7 Jan 2021

HAL is a multi-disciplinary open access archive for the deposit and dissemination of scientific research documents, whether they are published or not. The documents may come from teaching and research institutions in France or abroad, or from public or private research centers.
L'archive ouverte pluridisciplinaire HAL, est destinée au dépôt et à la diffusion de documents scientifiques de niveau recherche, publiés ou non, émanant des établissements d'enseignement et de recherche français ou étrangers, des laboratoires publics ou privés. 


\section{Novel interpenetrating polymer network composed of poly(Butyl Acrylates) and poly(Ethyl-HexylAcrylate)}

Kamel Eddine Boudraa ${ }^{1,2 *}$, Tewfik Bouchaour ${ }^{2}$, Christophe Beyens ${ }^{3}$ and Ulrich Maschke ${ }^{3}$

1 Département de Biologie, Faculté des Sciences, University of Saida, Algeria, e-mail : boudraa.kamel@univsaida.dz

2 Laboratoire de Recherche sur les Macromolécules, Département de Physique, Faculté des Sciences, Université Abou Bakr Belkaïd, Tlemcen, Algeria.

3 Unité de Matériaux et de Transformations UMET (UMR CNRS N8207), Bâtiment C6, Université des Sciences et Technologies de Lille, F-59655 Villeneuve d'Ascq Cedex, France

\section{ACKNOWLEDGMENTS}

This work was supported by University Dr Tahar Moulay-Saida- (Algeria) 


\begin{abstract}
A full acrylic interpenetrating polymer networks based on Poly Hexyl-Ethyl-Acrylate and Poly Butyl-Acrylate networks were synthesized by sequential polymerization technique. The investigated systems are prepared via photo-polymerization by UV-curing of monomers in the presence of a difunctional crosslinker and a photoinitiator. The IPNs properties have been improved by varying the initial composition and the crosslinker ratio. The systems are characterized by means of Infrared spectroscopy, swelling, DSC and ATG techniques. We found that the polymer networks have large swelling ratios, reflecting the higher compatibility of the two chosen monomers to form an IPN. Surprisingly, the resulted interpenetrating polymer networks with $0.5 \%$ crosslinker does not present any phase separation. We confirmed, by DSC and ATG techniques, that the quantity of the absorbed monomer by the precursory network played major roles in the physical properties of the different resulting IPNs and increasing the crosslinker prevent formation of unreacted oligomers inside the IPNs and thus leads to a more stable networks in their structures.
\end{abstract}

Keywords: Interpenetrating polymer Networks, Swelling behavior, Polymer synthesis, thermal properties, Poly Hexyl-Ethyl-Acrylate, Poly Butyl-Acrylate 


\section{INTRODUCTION}

Many researchers have studied the science of polymer gels; this is due to potential industrial applications of this kind of polymer systems. The attention was to focus on the innovation and development of new materials for these systems. The major shortcoming of this kind of polymer networks is their poor mechanical properties when they are in the swollen state. Consequently, reinforcement is needed for any future considered application. The increasing in the cross-linking density, co-polymerization with a more resistant system are among the ways to reinforce these systems, as well as the formation of interpenetrating polymer networks, IPNs.

An Interpenetrating Polymer Network, IPN, known as a blend of at least two polymers in a network form; One of them is synthesized and/or crosslinked in the immediate presence of the other(s). The synthesis of this new material class makes it possible to have in certain cases new materials with good performances in comparison with the initial polymer precursors [1-2]. These polymeric networks are synthesized by any known method of polymer synthesis. The most used approaches [3] for the synthesis of IPNs are: first, polymer network I is synthesized. Then, monomer II plus crosslinker and activator are swollen into network I and polymerized in situ. The resulting IPN is called sequential IPN. In the second case, the monomers and/or pre-polymers plus crosslinkers and activators of both components are mixed, followed by simultaneous polymerization via noninterfering reactions. Typical syntheses involve chain and step polymerization kinetics. While both polymerizations proceed simultaneously, the reactions ratios are rarely identical. The notion of IPNs containing two polymers, or more, chemically different was developed and there are approximately 400 documents published each year on this type of material [4-14]. They are now promising candidate materials in engineering [15], Drug Delivery [16], biomedical and industrial fields [17].

In order to use interpenetrating polymer networks for practical applications, it is required to understand the different properties of these polymer networks. Swelling experiment are a simple and "low-cost techniques" to characterize a polymer network. The swelling measurements can be used for quality control and serve as an indexing tool for polymer systems with different levels of crosslinking. Other techniques can be used to characterize an interpenetrating polymer networks. Indeed, thermal analysis includes a whole series of techniques of characterization of materials based on the study of the variation of a physical property according to the temperature. They are thus primarily macroscopic approaches of the behavior of the materials, which involve considerations of the equilibrium thermodynamic states, the irreversible thermodynamic processes and kinetics, associated with state changes (transition phenomena) and relaxationnal phenomena that can accompany them.

The 2-Ethylhexyl acrylate (EHA) is a very useful monomer for many industrial applications. It is marked essentially by his low glass transition temperature $\left(\mathrm{Tg}=-65^{\circ} \mathrm{C}\right)$ and has very good film formation property [1819]. Poly(2-ethylhexyl acrylate) (PEHA), are widely used in many applications [20]. The copolymers of PEHA with other acrylates, methacrylates, acrylonitrile, maleic acid esters, vinyl acetate, vinyl chloride, etc. find applications in adhesives, chemical intermediates, coatings, leather, plasticizers, plastics and textiles [21-22].

The Poly(n-butyl acrylate) (PABu) can be used as a soft segment in thermoplastic elastomers due to its low glass transition temperature and durability [23-24]. It is a very ductile ( 2000\% elongation at break), sticky, colorless and transparent rubbery material [25-26]. In view of their complementary properties, blending PABu with PEHA is a natural choice to improve properties including ductility without compromising transparency.

This work is as part of the systematic studies undertaken in our laboratories to explore the physical properties of composite materials made up of interpenetrating polymers networks. The novelty in our work is the choice of the 
two monomers 2-Ethylhexyl acrylate and n-butyl acrylate with an objective to synthetize a new sequential interpenetrating polymer network and the extraction of different physical parameters issued from this synthesis. To the best of our knowledge, experimental results on swelling kinetics of polymer networks in a solution containing these two kinds of monomers and crosslinker in order to form an interpenetrating polymer network as well as the swelling theoretical description have not been reported until now in literature. The realization of IPN systems will be checked step by step by giving a detailed analysis of the swelling kinetics of the different networks in the reactive solution containing monomer and crosslinker. The variation of the crosslinker amount allows obtaining either a loosely crosslinked network with more efficient swelling or more dense networks with limited swelling properties. In addition, different physical properties issued from this experience are also investigated given us useful information on IPNs formation. Information about the glass transitions temperature of the resulting IPNs and TGA thermograms are also presented and compared with their precursory networks.

\section{EXPERIMENTAL SECTION:}

\section{Monomers:}

The monomers, n-butyl-acrylate (99\%) and 2-ethyl-hexylacrylate (98\%), designated (n-ABu) and (2-EHA) respectively, were obtained from Aldrich. 1,6-Hexanedioldiacrylate (HDDA), supplied by Cray Valley (France) is used as crosslinking agent. 2-hydroxy-2-methyl-1-phenyl-propane-1 (Darocur 1173) from Ciba-Geigy was used as a photo-initiator.

\section{Prepolymers synthesis:}

Mixtures of $\mathrm{n}-\mathrm{ABu} / \mathrm{HDDA} / \mathrm{Darocur} 1173$ and 2-EHA/HDDA/Darocur 1173 were prepared in different weight fractions by varying the quantity of the monomer (n-ABu and 2-EHA) and HDDA, keeping the amount of Darocur 1173 constant (Monomer/HDDA/Darocur 1173=99/0.5/0.5 wt.-\%, 97/2.5/0.5wt.-\%, and 94.5/5/0.5wt.$\%)$. The initial mixtures were stirred mechanically for several hours, in order to ensure a uniform distribution of the monomer and the crosslinking agent over the sample volume, before they were cast in small flat sample holders made of Teflon. The samples were exposed under nitrogen atmosphere to a static UV lamp (Philips TL08) with a maximum emission wavelength at $\lambda=365 \mathrm{~nm}$ and an intensity $\mathrm{I} 0=1.5 \mathrm{~mW} / \mathrm{cm} 2$. The exposure time was fixed at $20 \mathrm{~min}$, although $5 \mathrm{~min}$ were sufficient to achieve complete conversion of the monomer.

\section{IPNs synthesis:}

Two kinds of sequential IPNs were synthesized. The first one consists of a PABu network, swollen, until reaching equilibrium, in a solution containing the second monomer (2-EHA)/Crosslinker/Photoinitiator. The swollen sample was then exposed to UV irradiation (the same used before). The exposure time was fixed to 20 min to achieve complete conversion of all monomers in the precursor system. The resulting network will be called IPN1. The second IPN was obtained with the same method described above, except that at first a PEHA network was formed, which was swollen in a second step, until reaching equilibrium, by a solution containing n$\mathrm{ABu}$, as mentioned before. The resulting network will be called IPN2. As we used various quantities of the crosslinker, we collect in the table 1 , all the networks used in this study. 


\begin{tabular}{|c|c|}
\hline $\begin{array}{l}\text { IPN1 (PABu polymer network, swollen in a solution } \\
\text { containing the 2-EHA monomer) }\end{array}$ & $\begin{array}{l}\text { IPN2 (PEHA polymer network, swollen in a solution } \\
\text { containing the } \mathrm{n}-\mathrm{ABu} \text { monomer) }\end{array}$ \\
\hline $\begin{array}{l}\text { IPN1-0.5\% }(99 \mathrm{n}-\mathrm{ABu} / 0.5 / 0.5 \text { wt.-\% synthesized } \\
\text { then swollen in } 99 \text { 2-EHA/0.5/0.5 wt.- } \%)\end{array}$ & $\begin{array}{l}\text { IPN2-0.5\% (99 2-EHA/0.5/0.5 wt.-\% synthesized } \\
\text { then swollen in } 99 \mathrm{n}-\mathrm{ABu} / 0.5 / 0.5 \text { wt.- } \%)\end{array}$ \\
\hline $\begin{array}{c}\text { IPN1-2.5\% }(97 \mathrm{n}-\mathrm{ABu} / 2.5 / 0.5 \text { wt.- } \% \text { synthesized } \\
\text { then swollen in } 97 \text { 2-EHA/2.5/0.5 wt.- } \%)\end{array}$ & $\begin{array}{c}\text { IPN2-2.5\% (97 2-EHA/2.5/0.5 wt.- } \% \text { synthesized } \\
\text { then swollen in } 97 \mathrm{n}-\mathrm{ABu} / 2.5 / 0.5 \text { wt.- } \%)\end{array}$ \\
\hline $\begin{array}{c}\text { IPN1-5\% }(94.5 \mathrm{n}-\mathrm{ABu} / 5 / 0.5 \mathrm{wt} .-\% \text { synthesized then } \\
\text { swollen in } 94.52 \text {-EHA/5/0.5 wt.- } \%)\end{array}$ & $\begin{array}{c}\text { IPN2-5\% (94.5 2-EHA } / 5 / 0.5 \text { wt.-\% synthesized then } \\
\text { swollen in } 94.5 \mathrm{n}-\mathrm{ABu} / 5 / 0.5 \text { wt.- } \%)\end{array}$ \\
\hline
\end{tabular}

Table-1: Composition and designation of IPN

\section{Characterization:}

\section{Real-Time Infrared Spectroscopy:}

FTIR spectra of thin films (less than $10 \mu \mathrm{m}$ ) in the transmission mode were recorded at room temperature with a Perkin Elmer 2000 FTIR model (The number of scans was 16 with spectral resolution of $4 \mathrm{~cm}-1$ ), before and after UV exposure. Each dose was applied once and the interval of time between the end of exposure and the infrared analysis was kept constant (below one minute). The experiments were repeated three times to validate the results and check if they are reproducible.

\section{Prepolymers swelling study:}

Investigations on swelling kinetics were carried out on PEHA and PABu networks to see the compatibility which exists between the two prepolymers. The influence of the crosslinking density and the chemical nature of the monomer on the swelling behavior of the networks were also examined. For each network, the used solvent is the reactive solution containing the other (Monomer/Crosslinker/Photoinitiator).

Swelling behavior in terms of the swelling ratio $\mathrm{Q}$ in the case of an usual solvent is given as:

Swelling ratio $=\mathrm{Q}=\frac{W_{s}-W_{i}}{W_{i}}$

Where $W s$ is the weight of the swollen network and $W i$ is the weight of initially dried network.

\section{Thermal analysis:}

For the thermal analysis, the Differential Scanning Calorimetry (DSC) technique was used for the study our polymer networks systems and in particular, to detect the glass transitions temperature (Tg) [27-28]. DSC measurements were performed on a Perkin Elmer Pyris Diamond calorimeter equipped with an Intracooler $2 \mathrm{P}$ system allowing cooling experiments. Samples for calorimetric measurements were prepared by introducing approximately $8 \mathrm{mg}$ of the material into an aluminum DSC pan, which was sealed to avoid evaporation effects during the temperature treatment. A rate of $10^{\circ} \mathrm{C} / \mathrm{min}$ (heating and cooling) was used in the temperature range from -75 to $150^{\circ} \mathrm{C}$. The program consists first in cooling the sample followed by three heating and cooling cycles to take into account eventual thermal events related to the sample preparation history. The results presented in this work were obtained from the first heating ramps. In each case, at least three duplicates having the same composition and prepared independently were used to check the reproducibility of results. 


\section{ATG measurement:}

Investigations were made in a Perkin Elmer Pyris ATG instrument while heating the samples from 25 to $600^{\circ} \mathrm{C}$ at the rate of $20^{\circ} \mathrm{C} / \mathrm{min}$ in nitrogen. Samples for thermal measurements were prepared by introducing approximately $10 \mathrm{mg}$ of the sample into an ATG pan. At least three duplicate samples having the same composition and prepared independently were used to check the reproducibility of results. The polymer degradation temperature was determined from the midpoint of the transition range of the thermograms.

\section{RESULTS AND DISCUSSION}

\section{Real-Time Infrared Spectroscopy:}

From the point of view of the spectroscopic characterization of the monomers, a FTIR-analysis spectroscopy of the monomers is carried out. The cells to be analyzed are prepared according to the physical state of the material to analyze at room temperature. The analysis by infrared spectroscopy was carried out every 5 minutes during 20 minutes. The absorption band of the FTIR spectrometer is included between 400 and $4000 \mathrm{~cm}^{-1}$. We were interested in the spectrum between 700 and $1800 \mathrm{~cm}^{-1}$ for better representing the absorption bands. Since the crosslinking ratio does not have any influence on the final obtained spectrum, we represent in the figures of the FTIR only the spectra of the polymeric samples with a $0.5 \%$ wt. HDDA crosslinking ratio. Several absorption bands are available to monitor the polymerization/crosslinking processes and to evaluate the conversion of the acrylic double bonds of the polymers PEHA, PABu, IPN1 and IPN2. One of the most characteristic absorption bands which is quite often used in IR-analysis of acrylates are the one corresponding to the $-\mathrm{CH}=\mathrm{CH}-$ deformation vibration (at $810 \mathrm{~cm}^{-1}$ and $1637 \mathrm{~cm}^{-1}$ ). The calculation of the monomer conversion is made by considering the peak heights of these absorption bands. According to the Beer-Lambert law, the absorbance $A$ of a species at a given wavelength is proportional to the molar concentration of this species. When a dose $D$ is applied, its disappearance can be evaluated by the conversion ratio:

$$
C(\%)=100 \times\left(1-\frac{\left(A_{\lambda}\right)_{(D)}}{\left(A_{\lambda}\right)_{(D=0)}}\right)
$$

where $\left(A_{\lambda}\right)_{D=0}$ is the height of the absorption band of the precursor system at the defined absorption band (810 or $1637 \mathrm{~cm}^{-1}$, i.e., radiation dose $\mathrm{D}$ is zero) and $\left(\mathrm{A}_{\lambda}\right)_{\mathrm{D}}$ is the corresponding result for the system exposed to a dose D. 


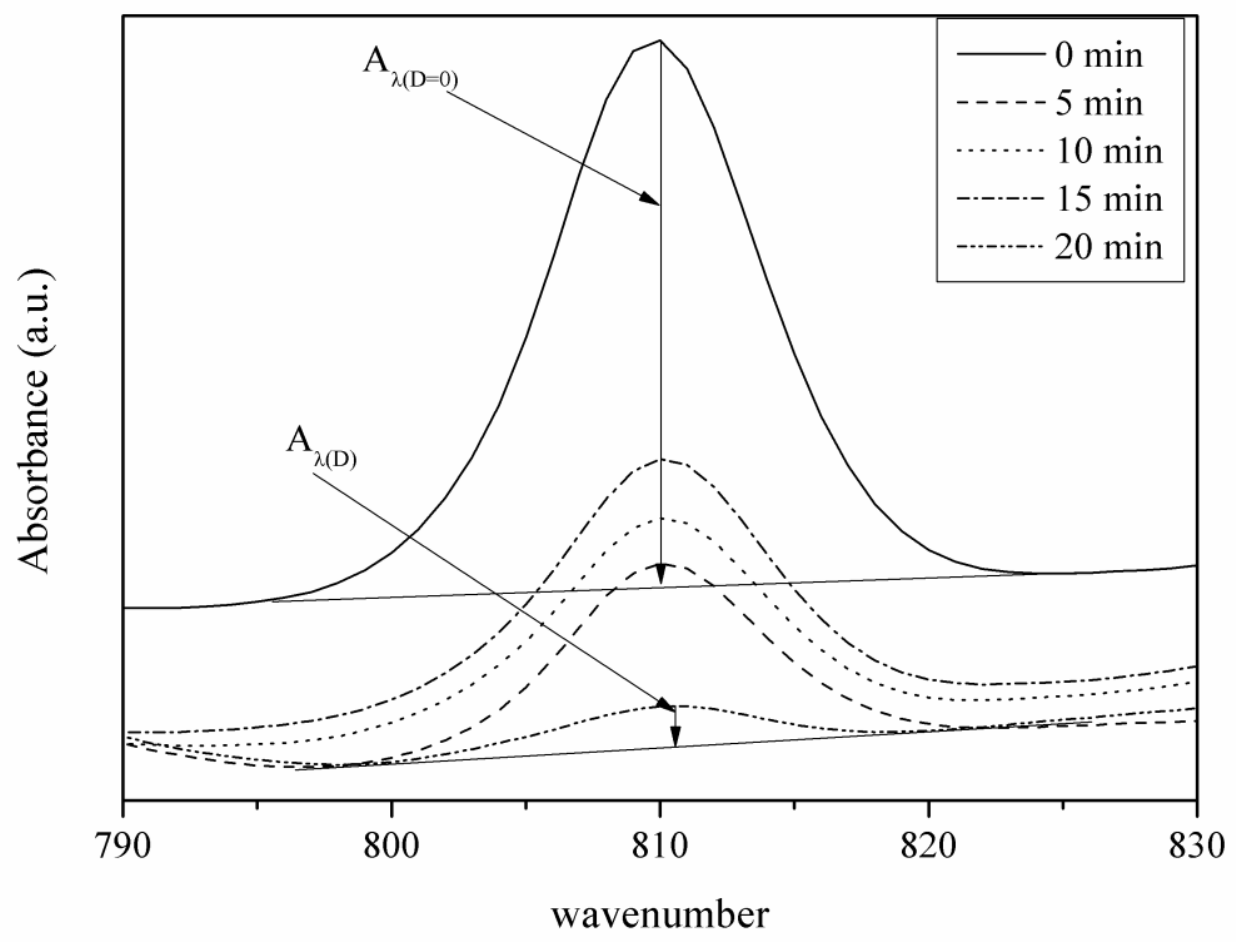

Fig. 1: FTIR spectra for the IPN1 $0.5 \%$ wt. HDDA for 20 minutes at the absorption band $810 \mathrm{~cm}^{-1}$

The Figure 1 represents the kinetics of polymerization of the interpenetrating polymer network IPN1 used in this study under UV radiation according to the amount of irradiation applied. To be able to calculate conversion into acrylic double bonds, we carry out an enlargement of the band to $810 \mathrm{~cm}^{-1}$. It appears clearly that the absorbance decrease as a function of the sample exposure time under UV radiation, which explains the progression of the conversion of the system analyzed into network at the end of 20 minutes. The peak observed and which correspond to $\mathrm{t}=20$ minutes indicates a very small amplitude, which means that the quantity of monomers and oligomers remaining in the liquid state and have not been able to be polymerized is really negligible. 


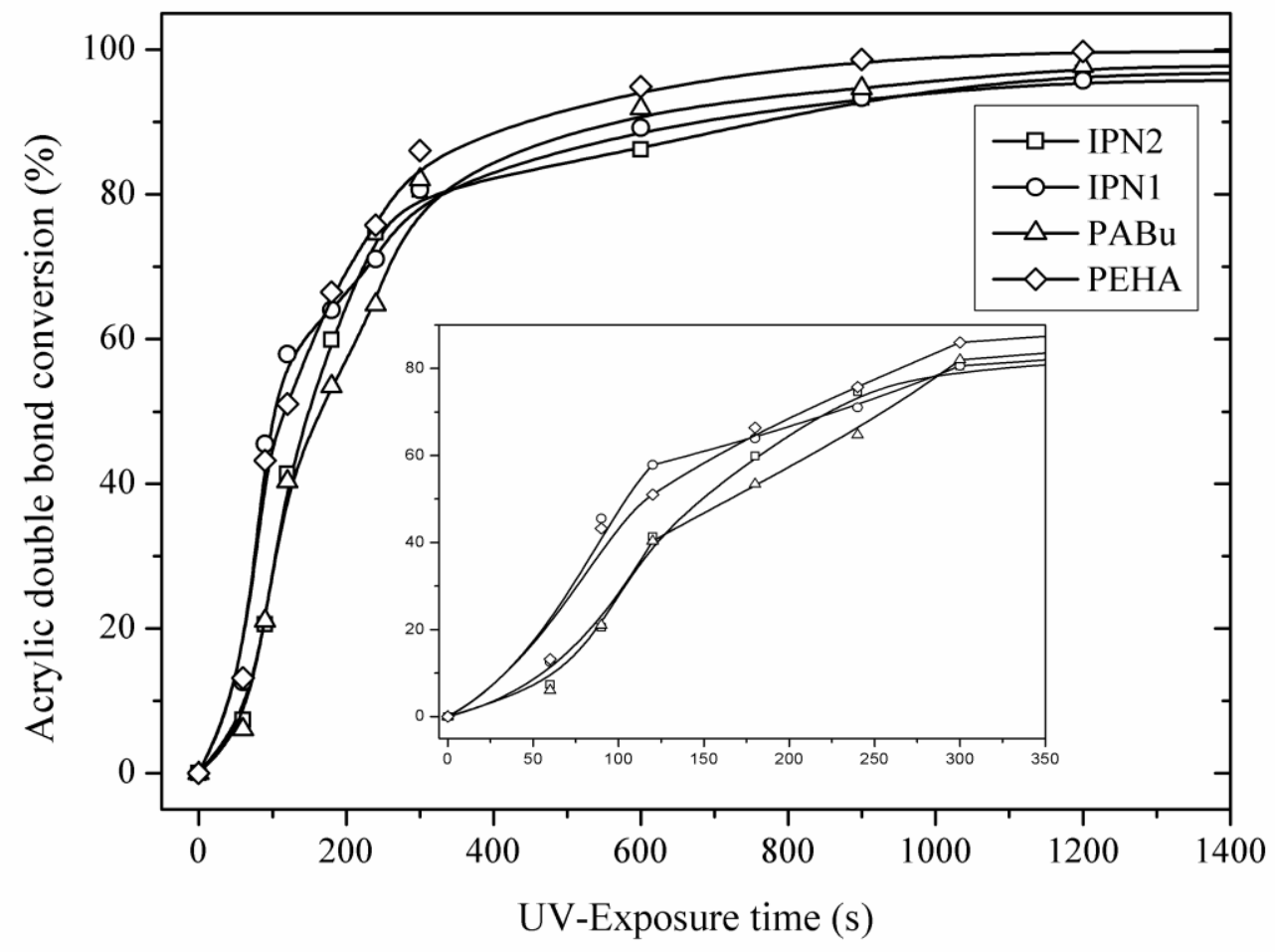

Fig. 2: Acrylic double bond conversion (\%) of IPN1, IPN2, PEHA and PABu prepared by UV curing using $0.5 \%$ wt. HDDA

Figure 2 represents the results of a FTIR spectroscopic analysis of the different systems. This figure shows the evolution of the acrylic double-bond conversion as a function of UV light exposure time. The inset of this figure shows the same results based on the range between 0 and $300 \mathrm{~s}$. It can be observed that increasing irradiation up to 20 minutes doses lead to an uptake of the monomer conversion. The PABu polymer network exhibit the highest crosslinking density of all systems studied here, leading to a relatively high glass transition temperature (see DSC section), and thus to a reduced monomer mobility during polymerization. As a result, this last show a lower conversion values compared to the other systems. The PEHA polymer networks reveal a sharp increase of the conversion/exposure time curve, showing a faster polymerization kinetics compared with the other systems, This can be explained by the enhanced mobility of the reacting species in relation with the strongly reduced $\mathrm{Tg}$ due to the greater distance between acrylic functions. Further increase of the polymer network density leads to reduced probability of chain propagation. As a consequence, the figure shows intermediate kinetics of the IPNs (IPN1 and IPN2) compared to the PABu and PEHA polymer networks. 


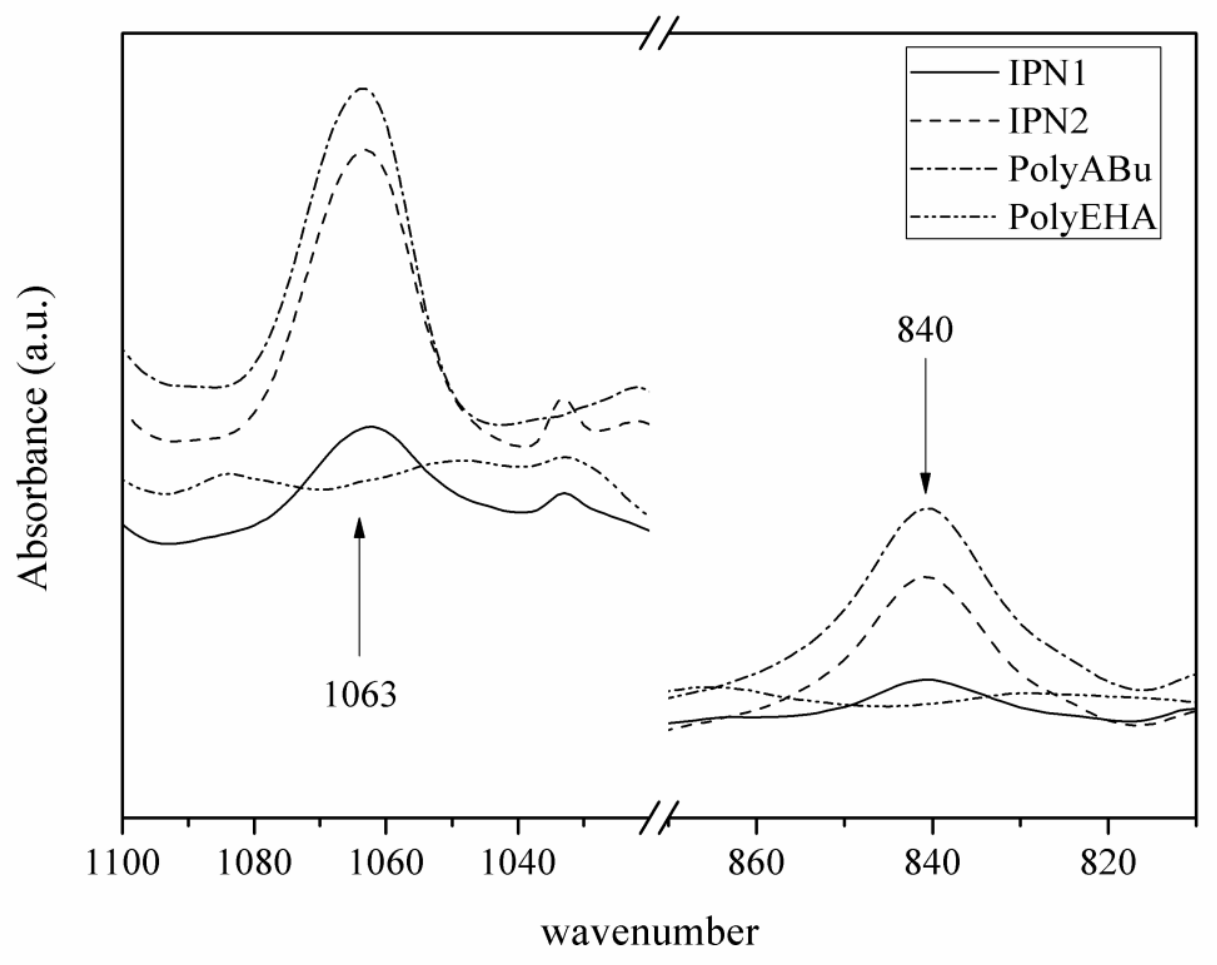

Fig. 3: FTIR Spectra of different networks

The FTIR spectra of the different systems are shown in Figure 3. (To clarify the differences, only the wavenumber range is shown). Absorption bands at $840 \mathrm{~cm}^{-1}$ and $1063 \mathrm{~cm}^{-1}$ (corresponding to the $\mathrm{CH}$ out-ofplane vibrations of $\mathrm{C}-\mathrm{CH} 3$ and $\mathrm{O}-\mathrm{CH} 3$ ), which are characteristic bands of $\mathrm{PABu}$, are found in the IR spectra of IPN2 and IPN1. The intensity of the peaks of absorption corresponding to IPNs becomes weaker from IPN2 to IPN1 with decreasing amount of $\mathrm{ABu}$ in the network.

\section{Prepolymers swelling study:}

The Tanaka-Fillmore theory [29-32] is one of the pioneering theories used for describing the swelling process of polymer networks in different solvents and was used by different researchers to rationalize their experimental data [33-36]. In this theory, only the osmotic pressure due to the solvent penetration used to explain the network expansion during swelling is taken into account and therefore the distribution of solvent in the network is not considered. A criticism to this theory was introduced by Komori and Sakamoto [37], where the authors assumes that the gel network is not extended due to the osmotic pressure of the gel, but to a swelling pressure which is generated by the solvent excess penetrating in the polymer network that tends to contract. Indeed, in addition to the swelling pressure assumed as driving force to expand the polymer network, the polymer network elasticity is considered. These two models displayed a good agreements of the theoretical results obtained with the experiment. In our case, and to rationalize our experimental data, we consider an interesting approach given by H. Omidian [38]. Indeed, in this model, based on the Voigt viscoelastic model presented in references [39-40], the authors present an exploratory investigation of the influence of crosslinker on the ability for swelling and on the absorption ratio for the acrylic polymers. For this purpose, they associate the spring element with resistance to expansion by the polymer network and the dashpot element with resistance to permeation. 
The figure 4 and figure 5 shows the swelling kinetics of both polymer networks at room temperature $\left(\mathrm{T}=21^{\circ} \mathrm{C}\right)$ in both reactive mixtures made up of monomer + HDDA + Darocur 1173 during 2880 minutes. The solid lines represent the theoretical fit obtained by fitting the experimental swelling data to the expression (3) using the Voigt viscoelastic model:

$Q_{t}=Q_{\infty}\left(1-\exp ^{-t} \tau\right)$

Given by H. Omidian [38,41-42], where $\mathrm{Q}_{\mathrm{t}}(\mathrm{g} / \mathrm{g})$ is the swelling capacity at time $\mathrm{t}, \mathrm{Q}_{\infty}(\mathrm{g} / \mathrm{g})$ denotes the theoretical equilibrium solvent absorption, $\mathrm{t}(\mathrm{min})$ is the swelling time, and $\tau$ ( $\mathrm{min}$ ) stands for a rate parameter, denoting the time required to reach $63 \%$ of equilibrium solvent absorption. The results are listed in the table 2.

\begin{tabular}{|c|c|c|c|}
\hline \multicolumn{2}{|c}{} & $Q_{\infty}$ & $\tau$ \\
\hline \multirow{3}{*}{ PABu (wt.-\% HDDA) } & $0.5 \%$ & $4,73 \pm 0,08$ & $206,19 \pm 16,88$ \\
\cline { 2 - 4 } & $2.5 \%$ & $2,11 \pm 0,06$ & $191,46 \pm 29,24$ \\
\cline { 2 - 4 } & $5 \%$ & $1,43 \pm 0,04$ & $165,89 \pm 22,56$ \\
\hline \multirow{3}{*}{ PEHA (wt.-\% HDDA) } & $2.5 \%$ & $4,79 \pm 0,15$ & $129,06 \pm 20,57$ \\
\cline { 2 - 5 } & & $1,89 \pm 0,03$ & $120,02 \pm 8,37$ \\
\cline { 2 - 5 } & $5 \%$ & $1,1 \pm 0,05$ & $113,02 \pm 24,81$ \\
\hline
\end{tabular}

Table 2: different parameters extracted from the fits to eq. (3)

These curves constitute a measure of the quantity of the reactive solution absorbed by the two different polymer networks. As the time proceeds, the two reactive solutions diffuse into the networks due to the concentration gradient, the osmosis effect ceases and mixing dominates resulting in the exponential swelling of the network. Further, as expected, by increasing the crosslinking degree of the first network the swelling of the monomer of the second network will be lower. For the polymer networks with lower crosslinker concentration, a high swelling ratio is observed, reaching approximately 5 times its initial weight. This ratio decreases when the rigidity of the polymer network is increased reaching thus approximately 2 times its initial weight for the networks having $2.5 \%$ wt. HDDA, to achieve approximately 1.2 times its initial weight for the networks having $5 \%$ wt. HDDA. 


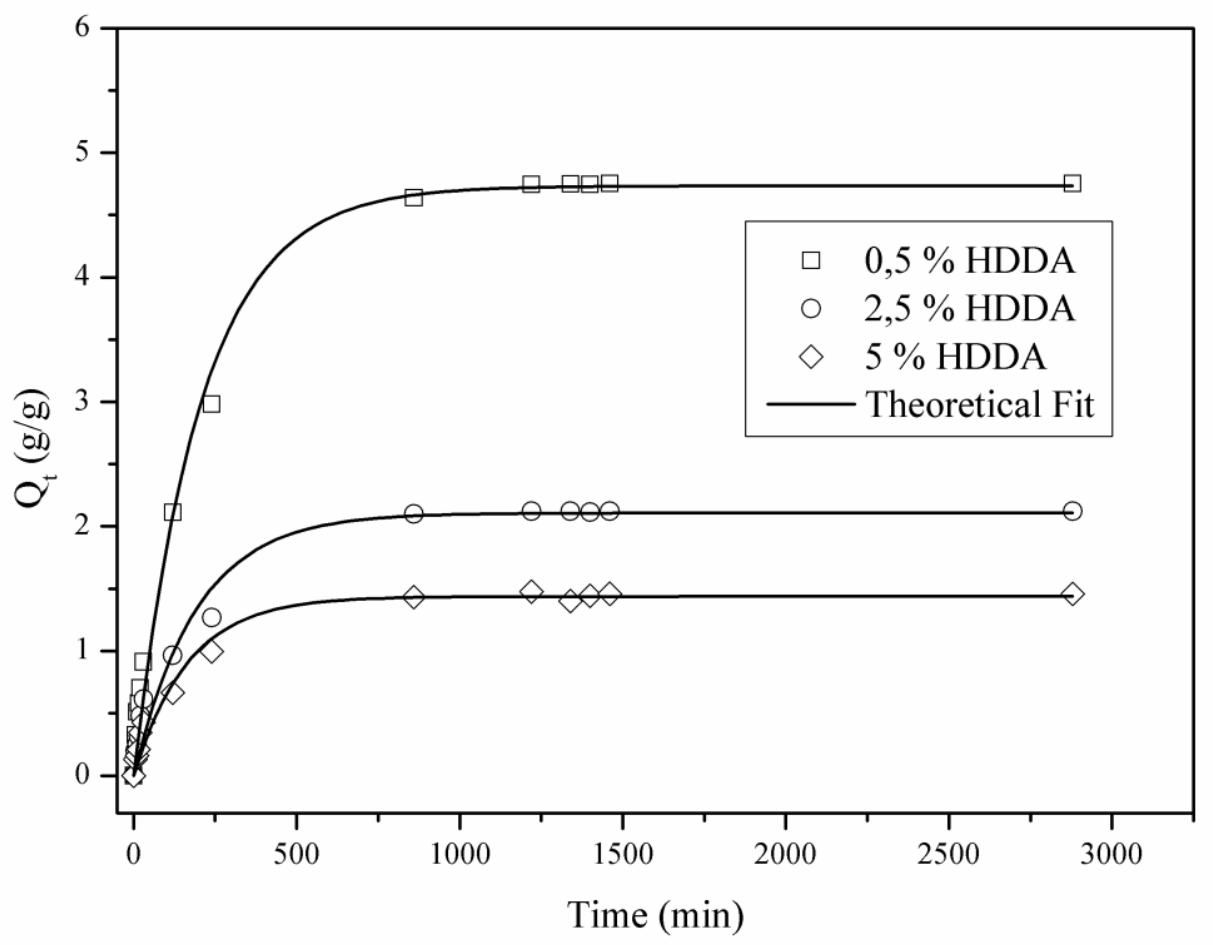

Fig. 4: Swelling of the PABu network in the reactive solution containing the monomer 2-EHA

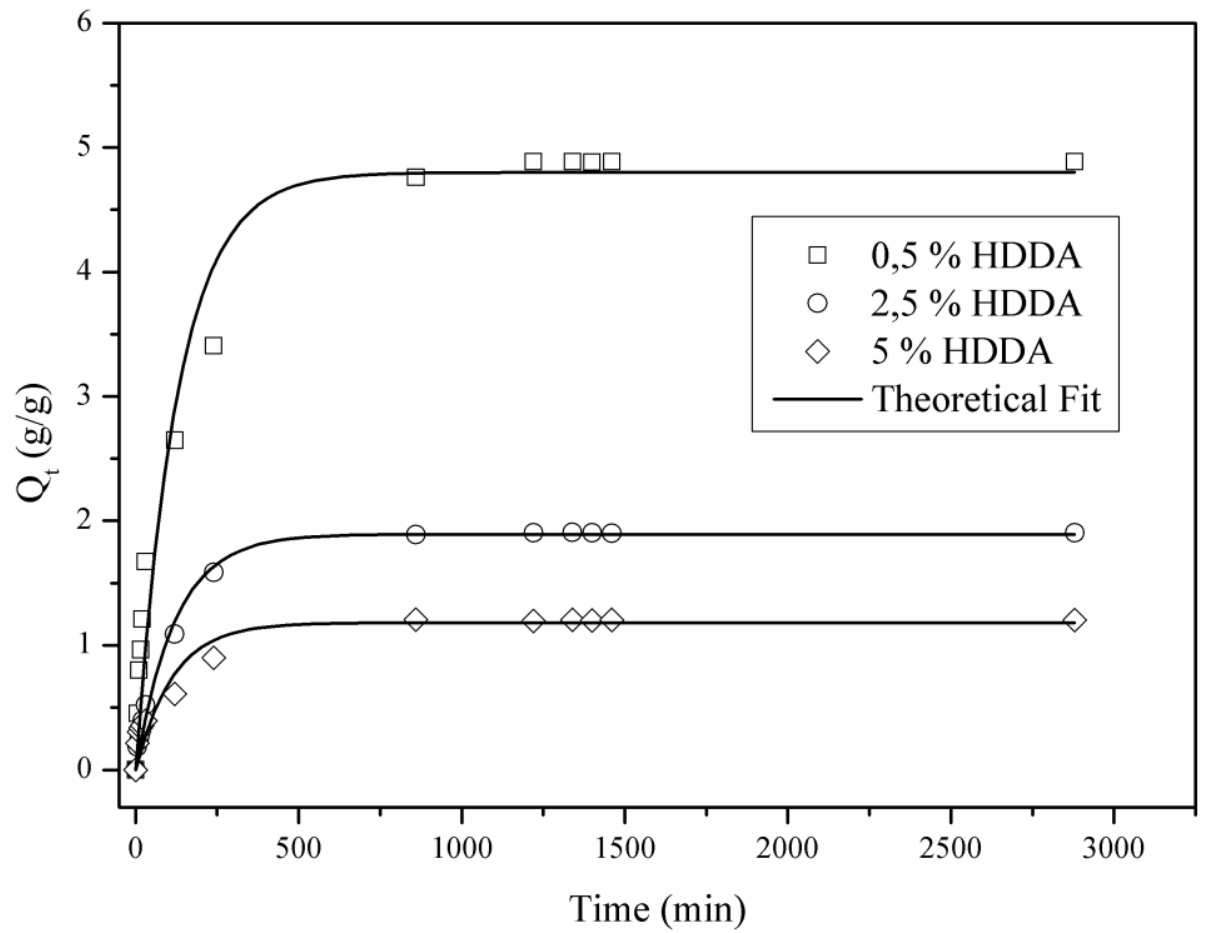

Fig. 5: Swelling of the PEHA network in the reactive solution containing the monomer n-ABu 
The swelling time constant gives us information about the ability of the polymer network to swell that is to say that if a polymer network has a high swelling time constant value then its swelling is slow and spend more time to reach saturation. In the case of figure 6 , where we present the time constants extracted from the fits to eq (3) for the different systems, both time constants shows a linear decrease with increasing the crosslinking ratio of the different polymer networks. This was expected because it known that the highly crosslinked polymer network quickly reach equilibrium. The interesting observation here is that the swelling time constants of the PABu network are considerably higher than those presented for PEHA polymer network. The PABu network spends more time to swell than the PEHA network. This is due to the highest density which is reflected on the chains mobility of the PABu network. Thus, the penetration of the n-EHA monomer inside the PABu network is slow, that mean that the interactions between the PABu network and the n-EHA monomer are weak than in the other case.

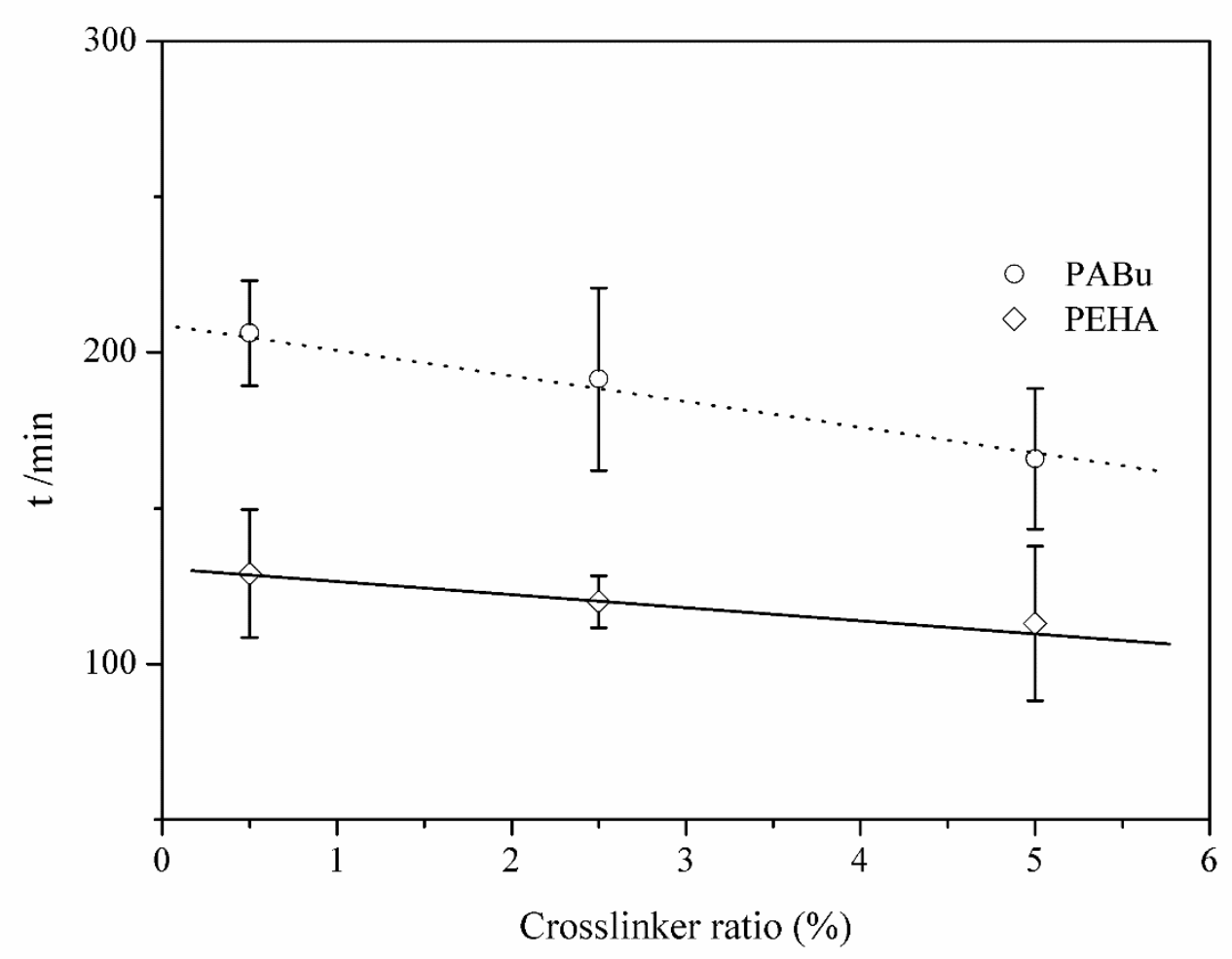

Fig. 6: time constant versus the variation of the HDDA Crosslinker (The lines are guides for eyes)

We perform an experimental determination of the mesh size, $\xi$, and the molecular weight of the polymer chains between crosslinks, $M_{c}$, of the various systems studied here and we report in the table 3 and figure 7 the different values derived from swelling experience. The knowledge of these two parameters is crucial to understanding the nanostructure of the crosslinked network; they were reported in literature [43-45] by many researchers and can be related to the swelling ratio. For gels at highly swelling conditions $(Q>10)$, these parameters are given as:

$Q=\left[\frac{\bar{v}\left(1 / 2-2 \chi_{12}\right) \bar{M}_{c}}{V_{1}}\right]^{3 / 5}=\beta\left(\bar{M}_{c}\right)^{3 / 5}$

$\bar{v}$ is the specific volume of the polymer, $\mathrm{V}_{1}$ is the molar volume of solvent, and $\chi_{12}$ is the polymer-solvent interaction parameter. 


$$
\xi=v_{2, s}^{-1 / 3}\left(\overline{r_{0}^{2}}\right)^{1 / 2}=Q^{1 / 3}\left(\overline{r_{0}^{2}}\right)^{1 / 2}
$$

Here $\left(\overline{r_{0}^{2}}\right)^{1 / 2}$ is the root-mean-squared end-to-end distance of network chains between two adjacent crosslinks in the unperturbed state. It can be determined using the following relationship [43]:

$$
\left(\overline{r_{0}^{2}}\right)^{1 / 2}=l\left(C_{n} N\right)^{1 / 2}=l\left(C_{n} \frac{2 \overline{M_{c}}}{M_{r}}\right)^{1 / 2}
$$

Where $C_{n}$ is the Flory characteristic ratio $\left(C_{n}=9,24\right.$ for the PolyABu and 9,5 for the PolyEHA), $l$ is the bond length along the polymer backbone $\left(l=1,54 \mathrm{~A}^{\circ}\right), N$ is the number of bonds between adjacent crosslinks, and $M_{r}$ is the molecular weight of the repeating units of the composed polymer $\left(M_{r}=128,7 \mathrm{~g} / \mathrm{mol}\right.$ for the PolyABu and $184,28 \mathrm{~g} / \mathrm{mol}$ for the PolyEHA). All these data were token from references [46-47].

Combining Equations (5) and (6), one can easily calculate the mesh size of the polymer network.

\begin{tabular}{|c|c|c|c|c|}
\hline & \multicolumn{2}{|c|}{$\mathrm{PABu}$} & \multicolumn{2}{c|}{ PEHA } \\
\hline & $M_{c}(\mathrm{~g} / \mathrm{mol})$ & $\xi\left({ }^{\circ} \mathrm{A}\right)$ & $M_{c}(\mathrm{~g} / \mathrm{mol})$ & 810 \\
\hline $0.5 \%$ & 28900 & 770 & 30250 & 270 \\
\hline $2.5 \%$ & 7540 & 300 & 6280 & 157 \\
\hline $5 \%$ & 4000 & 190 & 2920 & \\
\hline
\end{tabular}

Table 3: Different values of the two parameters $M_{c}$ and $\xi$ derived from swelling experience

As we can see, the two parameters $M_{c}$ and $\xi$ are principally affected by the degree of crosslinking of the two polymer networks. Indeed, they decrease with increasing the crosslinking ratio and became smaller for the highly crosslinked networks. That was expected because as we did introduce the crosslinker in the polymer network as we increase the density of the polymer network and thus the size of the chains decrease. The mesh size $(\xi)$ is playing the role of obstacles for the reactive solution and consequently controlling the diffusion of the monomer solution in the network.

\section{Thermal analysis results:}

DSC measurements were performed to know the behavior of phase separation on the different polymer networks. The polymer glass transition temperature was determined from the Half Cp Extrapolated point of the transition range of the thermograms. The value for the glass transition is the average for several measurements realized for each composition. 


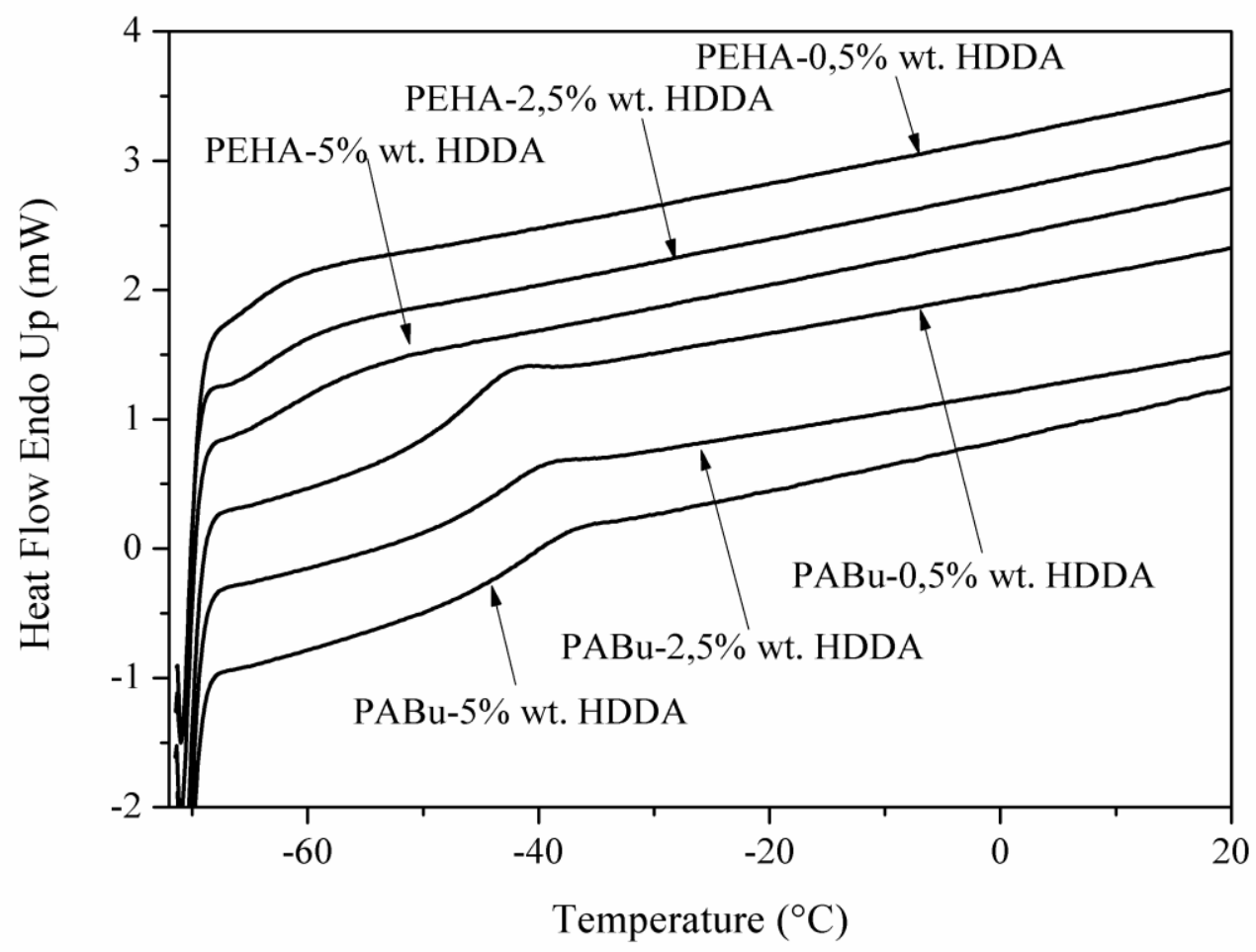

Fig. 7: DSC thermograms for the prepolymer networks

Figures 7 and 8 represent respectively the glass transition temperatures variation of the different prepolymer networks and for the Interpenetrating polymer networks IPN1 and IPN2 with various crosslinking densities. Only one single transition in the DSC thermograms for all the polymers is detected, especially for the two synthesized IPNs which indicates that the IPNs does not present phase separation. This would suggest that the different monomer 2-EHA and n-ABu are perfectly miscible. In addition, these figures clearly illustrate the glass transition temperatures for each polymer network and its direct dependence with the crosslinking density. Indeed, for the pure polymer network $\mathrm{PABu}$ and the pure polymer network PEHA, the glass transition temperature decreases with the decrease of the crosslinker. In other words, in the highly crosslinked polymer networks, the mobility of the polymer chains decreases which causes that $\mathrm{Tg}$ is quickly reached, opposing for the loosely crosslinked networks where the mobility of the chains is not reduced, which makes the Tg is small, as its mentioned in the table 4 where we gathered all the values obtained during this experiment for all the polymers networks. 


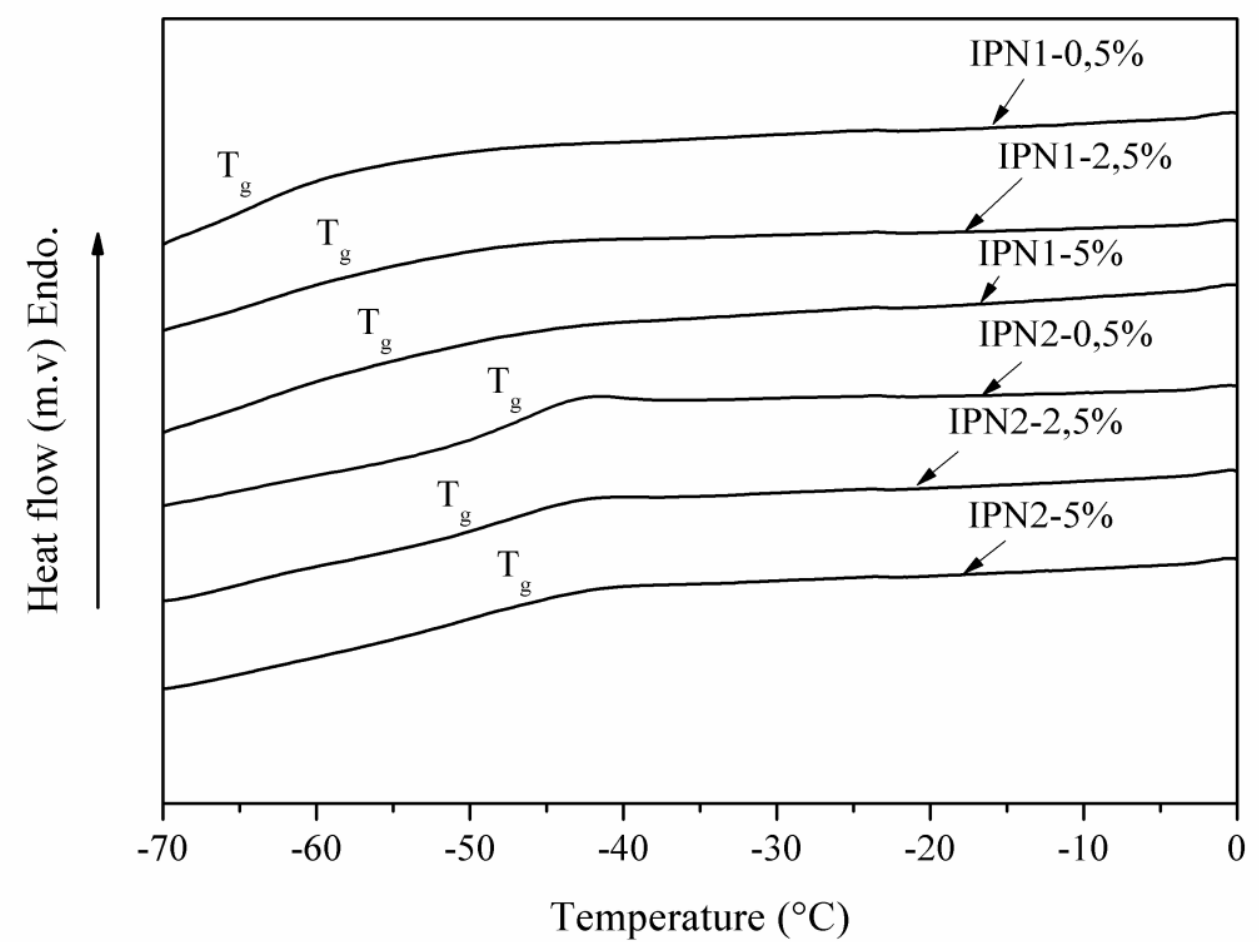

Fig. 8: DSC thermograms for the IPNs with different crosslinking ratio

\begin{tabular}{llllll}
\hline Polymer & & PABu & PEHA & IPN1 & IPN2 \\
\hline \multirow{3}{*}{ Tg } & $0.5 \%$ wt. HDDA & -45.25 & -63.07 & -65.24 & -46.68 \\
& 2.5\%wt. HDDA & -42.89 & -62.36 & -59.24 & -47.59 \\
& $5 \%$ wt. HDDA & -40.09 & -60.83 & -54.27 & -49.15 \\
\hline
\end{tabular}

Table 4: The glass transition temperature for the different polymer networks

An analysis of the figure 9, where we present the glass transition variation versus crosslinker percentage taken from table 4, informs us that the glass transition temperatures of both IPNs are close from/to each other and are controlled first by the quantity of the precursory polymer network present in the mixture. Indeed, for the loosely networks, the Tg of the IPN1 shows a slight shift compared with the Tg of the PEHA network. Apparently with the presence of the PABu in the IPN1 structure, this decreasing of Tg was expected because in the network IPN1 where the presence of the monomer 2-EHA is governing, by making references to the swelling curves discussed before, this last tends to influence its behavior and thus to have glass transition temperature more or less close to that of the pure network PEHA, and vice-versa. 


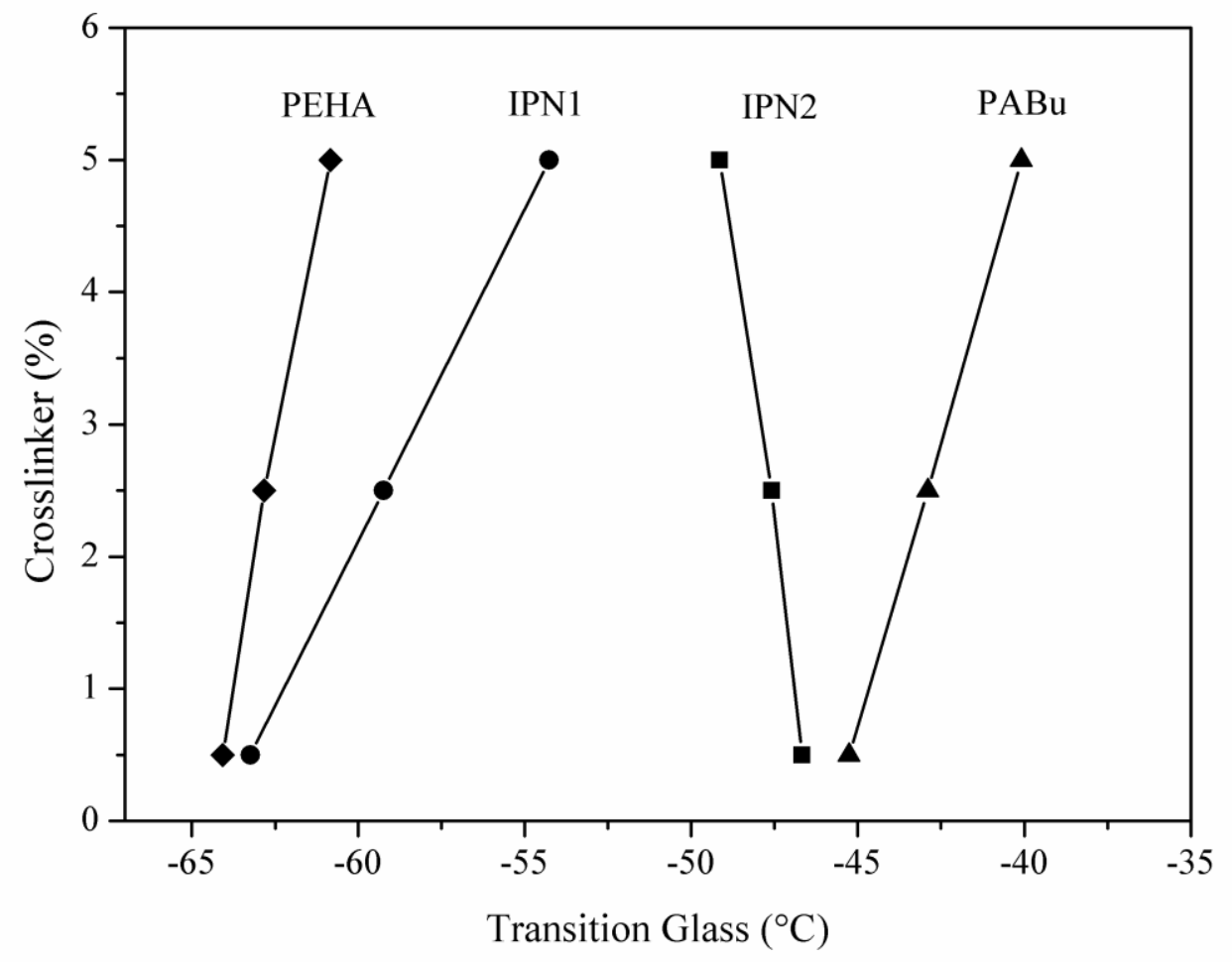

Fig. 9: Glass transition variation versus crosslinker HDDA percentage

\section{ATG results:}

The thermo gravimetric analysis (TGA) was performed to determine thermal stability of the polymeric materials and to examine the influence of their structural differences on thermal stability. The corresponding curves are given in figure 10 and figure 11 and the corresponding data are given in table 5. These curves displays that all the studied networks decompose in one single step, they are stable up to $300{ }^{\circ} \mathrm{C}$; shows a continuous weight loss in the range $\left(340-460{ }^{\circ} \mathrm{C}\right.$ ) characterized by an important weight loss, and decomposes completely beyond 500 ${ }^{\circ} \mathrm{C}$. The corresponding phenomena could be interpreted by a complete degradation of the materials (weight loss: $99.61 \%$ ). It can be observed that the increase in the crosslinking ratio increase slightly the thermal stability of the sample. However, kinetic aspect of the degradation depends on the compound of networks; Indeed, The IPN1 has a degradation kinetic similar to the one of PEHA network, and The IPN2 has a degradation kinetic similar to the one of $\mathrm{PABu}$ network. 


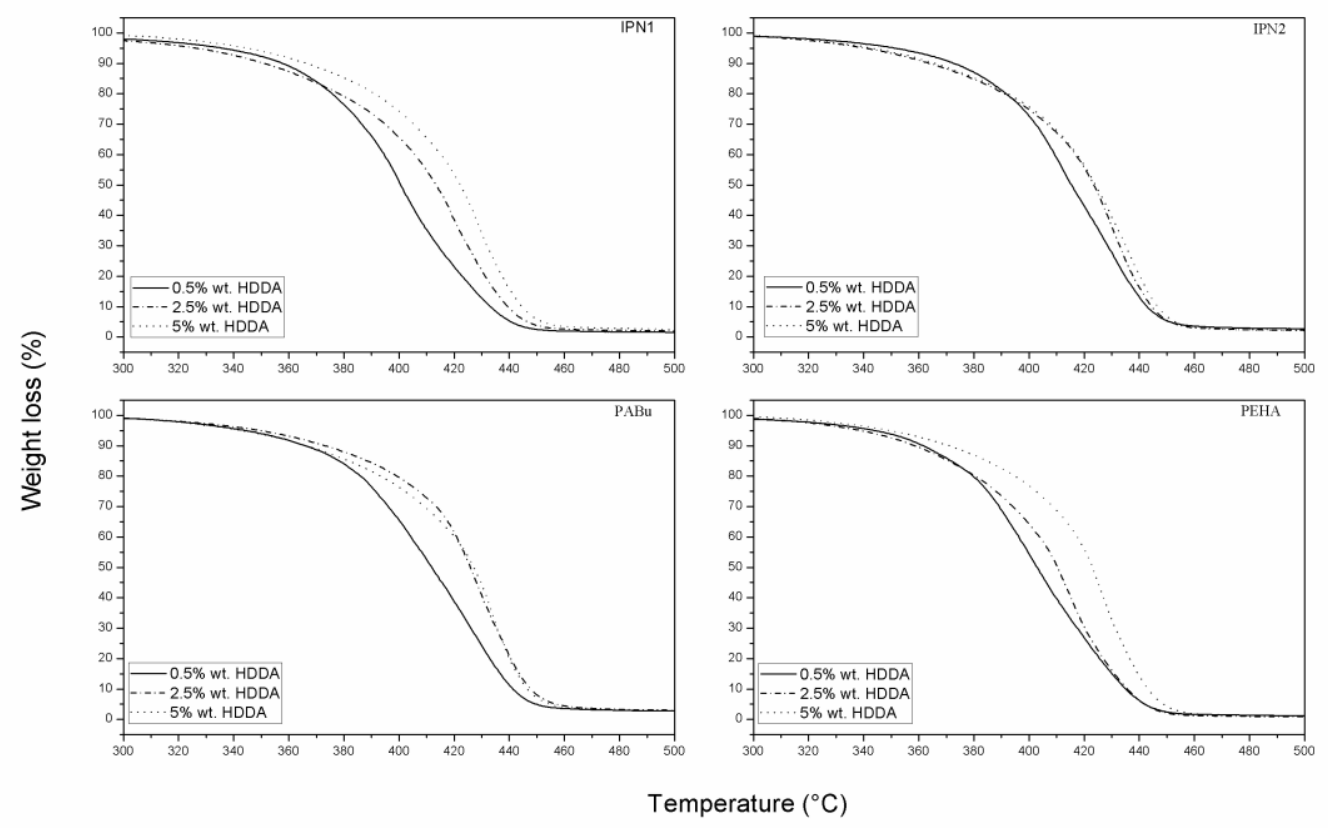

Fig. 10: Thermogravimetric curves of the different systems

The figure 11, where the DTG curves are given, the peak of the curves presented for the networks of polymers with a low crosslinking ratio is wide in comparison to the other peaks; this is probably due to the presence of some unreacted oligomers with the networks structure forming thereby an isolated blocks of polymer chains from the polymer network. This behavior does not exist by increasing the crosslinking degree, which confirms that one has stable polymer networks in their structures by increasing the crosslinking density.

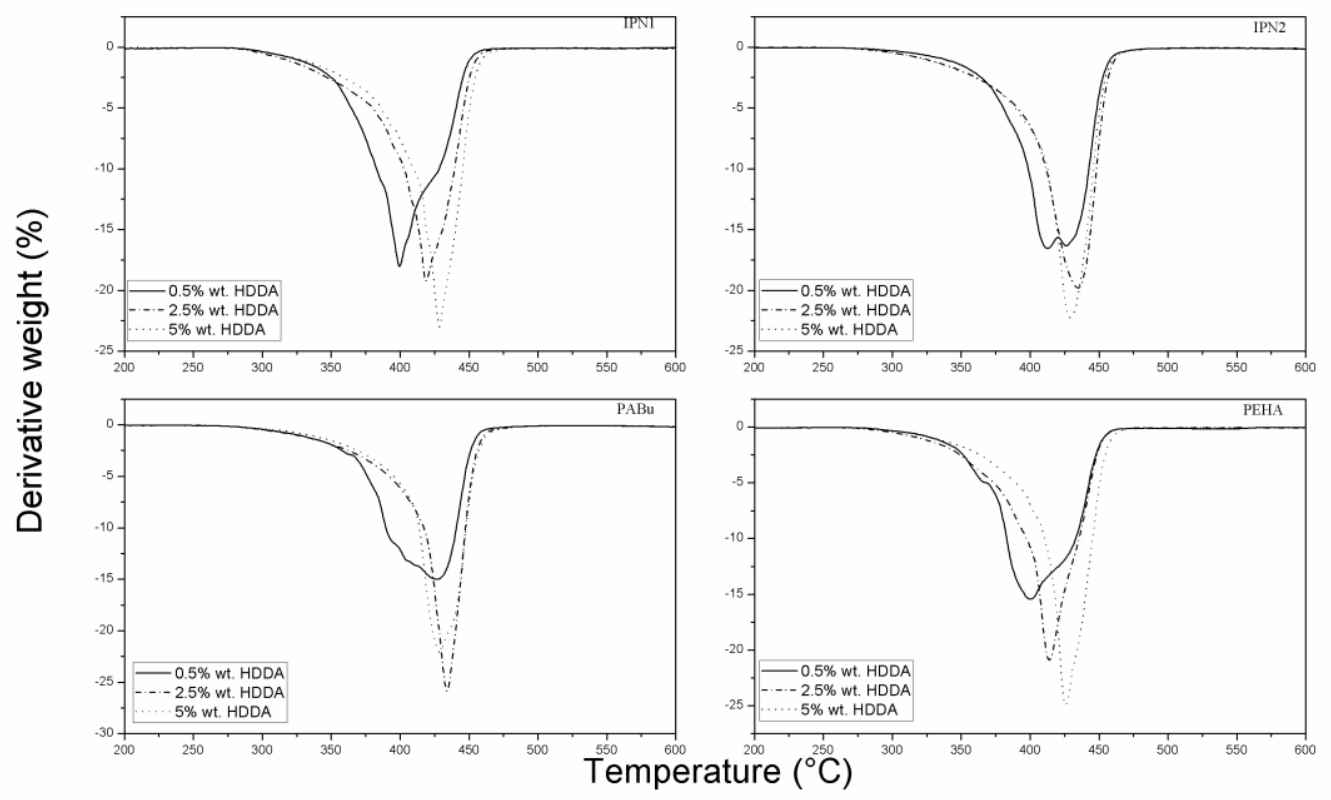

Fig. 11: Derivative thermogravimetric curves of the different systems 
The thermal stabilities of the different polymer networks were evaluated from TGA thermograms checking temperature corresponding to $5 \%, 50 \%$, and $95 \%$ of weight $\operatorname{loss}\left(\mathrm{T}_{5 \%}, \mathrm{~T}_{50 \%}\right.$, and $\left.\mathrm{T}_{95 \%}\right)$. The start of degradation for all samples appeared to begin, with a light difference, at around the same temperature; however, the kinetic aspect of the early stage of degradation indicates the presence of chain blocks which have not reacted with the polymer network and which influences the kinetics of the first degradation steps. After 50\% of weight loss, the thermal stability is found for all the polymer networks and thus an increase in the thermal stability with the increase of the crosslinking ratio.

\begin{tabular}{|l|l|l|l|l|}
\hline & $\%$ wt. HDDA & $\mathrm{T}_{5 \%}\left({ }^{\circ} \mathrm{C}\right)$ & $\mathrm{T}_{50 \%}\left({ }^{\circ} \mathrm{C}\right)$ & $\mathrm{T}_{95 \%}\left({ }^{\circ} \mathrm{C}\right)$ \\
\hline \multirow{5}{*}{ IPN1 } & $0.5 \%$ & 328 & 400 & 438 \\
\cline { 2 - 5 } & $2.5 \%$ & 319 & 413 & 445 \\
\cline { 2 - 5 } & $5 \%$ & 338 & 421 & 450 \\
\hline \multirow{5}{*}{ IPN2 } & $0.5 \%$ & 344 & 414 & 448 \\
\cline { 2 - 5 } & $2.5 \%$ & 334 & 423 & 449 \\
\cline { 2 - 5 } & $5 \%$ & 336 & 424 & 452 \\
\hline \multirow{5}{*}{ PolyABu } & $0.5 \%$ & 344 & 411 & 449 \\
\cline { 2 - 5 } & $2.5 \%$ & 349 & 425 & 456 \\
\cline { 2 - 5 } & $5 \%$ & 342 & 426 & 442 \\
\hline \multirow{5}{*}{ PolyEHA } & $0.5 \%$ & 344 & 402 & 442 \\
\cline { 2 - 5 } & $2.5 \%$ & 339 & 423 & \\
\cline { 2 - 5 } & $5 \%$ & 349 & & 410 \\
\hline
\end{tabular}

Table 5: Degradation Data of the different polymer networks

\section{QUALITATIVE ANALYSIS:}

The synthesis of the acrylic interpenetrating polymer network enabled us to deduce from it that its precursory networks present a high and a perfect compatibility between them. This two chosen polymer networks are known for their high reactivity and similar properties.

An observation of the swelling curves shows that the polymer networks PEHA and PABu have very close swelling ratio for the networks having the same proportions of the crosslinker. The $Q_{\max }$ decreases dramatically as we pass from the hard to the loose polymer network. For the loosely PEHA network, a slightly higher swelling ratio is presented, reverberating on the mesh size values. This behavior is expected and it is due primarily to the chemical structure of the two networks; The PEHA network present a longer polymer chain than $\mathrm{PABu}$. As we increase the amount of the crosslinker, we observe that the PABu network presents the higher $Q_{\max }$ values, reflecting on the mesh size values too. The PABu network swells slightly better than the PEHA network when increasing the crosslinker density. So we can say that the increase in the density increase the structure order too in the network and leads to a more stable network structure. The loosely polymer networks, absorb a huge amount of the reactive solution, which favors the formation of isolated chain blocks inside; this phenomenon is translated by a large peak in the DTG curves of the loosely networks. However, the higher crosslinking density leads us to obtain a harder polymer network and more stable in its structure; thus a lower swelling ratio. In other words, the increasing of crosslinking density will give chance to all monomers to react and be attached to the crosslinker and form a dense and homogeny network; this increasing causes an apparition 
of a resistive force of the polymer chains to elongation and consequently reducing the swelling ratio rather than polymer networks presenting lower crosslinking density.

Another interesting information issued from the swelling curves is that we can control the amount of the second monomer penetrating the first network just by controlling its swelling. If, for example, we desire to synthesize an IPN with a (50:50) ratio for each component, we swell the first network until it reaches $200 \%$ a swelling ratio even if this latter has not reached its swelling balance yet, differing in conventional IPN synthesis methods.

Another remark is that the increase in the percentage of the crosslinker leads to an increase of the glass transition of the IPN1 bringing it closer to that of the PABu network. The same phenomenon (but inversed) is observed in the case of the IPN2 in a less marked way. Indeed, the Tg of the IPN2 decrease this time by increasing the percentage of the HDDA crosslinker approaching that of the PEHA. This brings us to conclude, that each IPN network synthesized will be influenced mainly, in its properties, by the amount of the absorbed monomer until reaching equilibrium. For the loosely networks, the amount of the absorbed monomer will be the majority in the resulting IPN and therefore this last will be dependent, in its properties, of the properties of the absorbed monomer. This dependence is limited every time we increased the crosslinking ratio of each networks until (more or less) almost equal in the two highly crosslinked networks.

\section{CONCLUSION:}

In this work, we demonstrated a synthesis of a novel sequential interpenetrating polymer network, composed of poly(2-ethylhexyl acrylate) and poly(n-butyl acrylate) and we studied the physical properties by varying the crosslinker ratio. The conversion of double bonds of the acrylate monomers was monitored by FTIR spectroscopy in terms of radiation dose. The PEHA network shows the highest reactivity compared to the PABu network. The intensity of the peaks of absorption corresponding to IPNs becomes weaker from IPN1 to IPN2 with decreasing amount of the $\mathrm{n}-\mathrm{ABu}$ in the network. An upper limit of the double bond conversion was reached near $95-98 \%$. The compatibility that exists between these two networks is investigated by studying the swelling of each network in the reactive solution containing the mixture made up of monomer and crosslinker. The results show high swellings ratio. Initially, the systems swelled exponentially to saturation over $48 \mathrm{~h}$ due to concentration gradient. These ratios are very close for the networks having the same proportions of the crosslinker and inform us that the composition of the IPNs is controlled by varying the crosslinker ratio in the initial mixture; higher crosslinking density leads us to obtain a harder interpenetrating polymer network, homogeny and more stable in its structure. The DSC results inform us that the glass transition temperature of the different studied systems is influenced by the amount of the monomers absorbed by the network and that all the resulted IPNs, especially the IPN with $0.5 \%$ crosslinker, does not present any phase separation. Finally, the TGA thermograms show that all the networks decompose completely beyond $550^{\circ} \mathrm{C}$ and it was found an increase in the thermal stability with the increase of the crosslinking ratio.

CONFLICT OF INTEREST: The authors declare that they have no conflict of interest.

\section{References:}

[1]. Chakrabarty D, (1988) Polymer Gels and Networks, Vol 6, 191-204 
[2]. Utracki L.A, (1995) History of commercial polymer blends, Polymer Engineering and Science, MidJanuary, Vol 35, $\mathrm{N}^{\circ} 1$

[3]. Sperling L.H, (2006) Introduction to Physical Polymer Science. 4 ed., New York: Wiley - Interscience. 671

[4]. Thapliyal P.C, (2010) Interpenetrating Polymer Networks, Composite Interfaces, 17, 85-89. https://doi.org/10.1163/092764410X490509

[5]. Xiao W, He J, Nichol JW, et al., (2011) Synthesis and characterization of photocrosslinkable gelatin and silk fibroin interpenetrating polymer network hydrogels, Acta biomaterialia, 7, 2384-2393. https://doi.org/10.1016/j.actbio.2011.01.016

[6]. Koul V, Mohamed R, Kuckling D, Adler H-J.P, Choudhary V., (2011) Interpenetrating polymer network (IPN) nanogels based on gelatin and poly (acrylic acid) by inverse miniemulsion technique: Synthesis and characterization, Colloids and Surfaces B: Biointerfaces, 83, 204-213. https://doi.org/10.1016/j.colsurfb.2010.11.007

[7]. Guo Y, Yuan T, Xiao Z, Tang P, Xiao Y, Fan Y, Zhang X, (2012) Hydrogels of collagen/chondroitin sulfate/hyaluronan interpenetrating polymer network for cartilage tissue engineering, Journal of Materials Science: Materials in Medicine, 23, 2267-2279. https://doi.org/10.1007/s10856-012-4684-5

[8]. Zhang J, Zhang M, Tang K, Verpoort F, Sun T, (2014) Polymer-Based Stimuli-Responsive Recyclable Catalytic Systems for Organic Synthesis, Small, 10, 32-46. https://doi.org/10.1002/smll.201300287

[9]. Slaughter B.V et al., (2015) Dynamic Swelling Behavior of Interpenetrating Polymer Networks in Response to Temperature and pH, J. of App. Polym. Sci., 132, 24. https://doi.org/10.1002/app.42076

[10]. Roland C.M, (2015) Interpenetrating Polymer Networks (IPN): Structure and Mechanical Behavior. Encyclopedia of Polymeric Nanomaterials, 1004-1011

[11]. Yao Y, Zhou T, Cheng Yang C, Yanju Liu Y, Leng J, (2016) Preparation and characterization of shape memory composite foams with interpenetrating polymer networks, Smart Materials and Structures, 25, 35002. https://doi.org/10.1088/0964-1726/25/3/035002

[12]. Lai E, Y. Wang Y, Wei Y, Li G, Ma G, (2017) Effects of Cross-Link Density on Structures and Properties of Dual-Sensitive Semi-Interpenetrating Polymer Networks Hydrogel Microspheres, Macromol. Chem. Phys., 218, 1600596. https://doi.org/10.1002/macp.201600596

[13]. Dave V.J, Patel H.S, (2017) Synthesis and characterization of interpenetrating polymer networks from transesterified castor oil based polyurethane and polystyrene, Journal of Saudi Chemical Society, 21, 1824. https://doi.org/10.1016/j.jscs.2013.08.001

[14]. Jia C, Zhang X, Li Y, Jiang Y, Zhang M, Lu P, Chen H, (2018) Synthesis and characterization of bio-based PA/EP interpenetrating network polymer as coating material for controlled release fertilizers, J. Appl. Polym. Sci., 135, 46052. https://doi.org/10.1002/app.46052

[15]. Zhang B, S. Sun S, Wu P, (2013) Synthesis and unusual volume phase transition behavior of poly $(N-$ isopropylacrylamide)-poly(2-hydroxyethyl methacrylate) interpenetrating polymer network microgel, Soft Matter, 9, 1678-1684. http://dx.doi.org/10.1039/C2SM27355A

[16]. Lohani A, Singh G, Bhattacharya S.S, Verma A, (2014) Interpenetrating Polymer Networks as Innovative Drug Delivery Systems, Journal of Drug Delivery. http://dx.doi.org/10.1155/2014/583612 
[17]. Dragan E.S, (2014) Design and applications of interpenetrating polymer network hydrogels. A review, Chemical Engineering Journal, 243 572-590. https://doi.org/10.1016/j.cej.2014.01.065

[18]. Haloi D.J, Roy S, Singha N.K, (2009) Copper catalyzed atom transfer radical copolymerization of glycidyl methacrylate and 2-ethylhexyl acrylate, J. Polym. Sci., Part A: Polym. Chem., 47, 6526. https://doi.org/10.1002/pola.23695

[19]. Haloi D.J et al., (2013) Synthesis and characterization of poly(2-ethylhexyl acrylate) prepared via atom transfer radical polymerization, reverse atom transfer radical polymerization and radical polymerization, J. Chem. Sci., 125, 791-797. https://doi.org/10.1007/s12039-013-0438-2

[20]. Czech Z, Kowalczyk A, Kabatc J, Świderska J, (2013) Thermal stability of poly(2-ethylhexyl acrylates) used as plasticizers for medical application, Polym. Bull. 70, 1911-1918. https://doi.org/10.1007/s00289012-0887-7

[21]. Bicak N, Karagoz B, Emre D, (2006) Atom transfer graft copolymerization of 2-ethyl hexylacrylate from labile chlorines of poly(vinyl chloride) in an aqueous suspension, J. Polym. Sci., Part A: Polym. Chem., 44, 1900. https://doi.org/10.1002/pola.21298

[22]. Haloi D.J, Ata S, Singha N.K, Jehnichen D, Voit P, (2012) Acrylic AB and ABA Block Copolymers Based on Poly(2-ethylhexyl acrylate) (PEHA) and Poly(methyl methacrylate) (PMMA) via ATRP, Appl. Mater. Interfaces., 4, 4200-4207. https://doi.org/10.1021/am300915j

[23]. Matyjaszewski K, Nakagawa Y, Jasieczek C.B, (1998) Polymerization of $n$-Butyl Acrylate by Atom Transfer Radical Polymerization. Remarkable Effect of Ethylene Carbonate and Other Solvents, Macromolecules, 31, 1535-1541. https://doi.org/10.1021/ma971444r

[24]. Wang G, (2011) Synthesis of Poly(n-butyl acrylate) Homopolymers by Activators Generated by Electron Transfer (AGET) ATRP Using $\mathrm{FeCl}_{3} 6 \mathrm{H}_{2} \mathrm{O} /$ Succinic Acid Catalyst, Iranian Polymer Journal, 20, 931-938.

[25]. Wen X, Lin Y, Han C, Zhang K, Ran X, Li Y, Dong L, (2009) Thermomechanical and optical properties of biodegradable poly(L-lactide)/silica nanocomposites by melt compounding, J. Appl. Polym. Sci., 114, 3379-3388. https://doi.org/10.1002/app.30896

[26]. Meng B, Deng JJ, Liu Q, Wu Z, Yang W, (2012) Transparent and ductile poly(lactic acid)/poly(butyl acrylate) (PBA) blends: Structure and properties, European Polymer Journal, 48, 127-135. https://doi.org/10.1016/j.eurpolymj.2011.10.009

[27]. Derouiche Y, Koynov K, Dubois F, Douali R, Legrand C, Maschke U, (2012) Optical, Electro-Optical, and Dielectric Properties of Acrylic Tripropyleneglycol Based Polymer Network Systems Including LCs, Mol. Cryst. Liq.Cryst, 561, 124-135. https://doi.org/10.1080/15421406.2012.687149

[28]. Bouchikhi N, Semdani F, Alachaher Bedjaoui L, Maschke U, (2012) Elaboration of Side-Chain LiquidCrystalline Elastomers and Study of Their Swelling Behavior in Anisotropic Solvents, Mol. Cryst. Liq.Cryst, 560, 159-169. https://doi.org/10.1080/15421406.2012.663196

[29]. Tanaka, T.; Hocker, L.O, Benedek, G. B., (1973) Spectrum of light scattered from a viscoelastic gel, J. Chem. Phys., 59, 5151. https://doi.org/10.1063/1.1680734

[30]. Tanaka T., Fillmore D.J.J., (1979) kinetics of swelling of gels, Chem. Phys., 70, 1214-1218. https://doi.org/10.1063/1.437602 
[31]. Li Y, Tanaka T, (1990) Kinetics of swelling and shrinking of gels, J. Chem. Phys. 92, 1365. https://doi.org/10.1063/1.458148

[32]. Shibayama M, Tanaka T, (1993) Volume phase transition and related phenomena of polymer gels, In: Dušek K. (eds) Responsive Gels: Volume Transitions I. Advances in Polymer Science, vol 109. Springer, Berlin, Heidelberg, https://doi.org/10.1007/3-540-56791-7_1

[33]. Ganji F, Vasheghani-Farahani S, Vasheghani-Farahani E, (2010) Theoretical Description of Hydrogel Swelling: A Review, Iranian Polymer Journal, 19, 375-398

[34]. Sivanantham M, Tata B.V.R, (2012) Swelling/deswelling of polyacrylamide gels in aqueous $\mathrm{NaCl}$ solution: Light scattering and macroscopic swelling study, Pramana - J. Phys.,79. https://doi.org/10.1007/s12043-012-0325-2

[35]. Gabriel S. Longo, Monica Olvera de la Cruz and I. Szleifer, (2014) Non-monotonic swelling of surface grafted hydrogels induced by pH and/or salt concentration, J. Chem. Physics 141, 124909. https://doi.org/10.1063/1.4896562

[36]. Jian Ping Gong et al., (2016) Coupled instabilities of surface crease and bulk bending during fast free swelling of hydrogels, Soft Matter,12, 5081. http://dx.doi.org/10.1039/C6SM00578K

[37]. Komori T., Sakamoto R, (1989) On Tanaka-Fillmore's kinetics swelling of gels, Colloid Polym. Sci., 267, 179. https://doi.org/10.1007/BF01410357

[38]. Omidian H, Hashemi S.A, Sammes P.G, Meldrum I, (1989) A model for the swelling of superabsorbent polymers, Polymer, 39 No. 26, pp. 6697-6704. https://doi.org/10.1016/S00323861(98)00095-0

[39]. Tschoegl, N. W, (1989) The Phenomenological Theory of Linear Viscoelastic Behaviour, SpringerVerlag, Berlin, p. 86.

[40]. Aklonis J.J, Macknight W.J, (1983) Introduction to Polymer Viscoelasticity, Wiley-Interscience, New York, p. 147

[41]. Chien-Chi Lin, Andrew T. Metters, (2006) Hydrogels in controlled release formulations: Network design and mathematical modelling, Advanced Drug Delivery Reviews, 58, 1379-1408. https://doi.org/10.1016/j.addr.2006.09.004

[42]. Liu X. et al., (2011) Modified acrylic-based superabsorbents with hydrophobic monomers: synthesis, characterization and swelling behaviors, Journal of Polymer Research 18, 897-905. https://doi.org/10.1007/s10965-010-9487-0

[43]. Canal T, Peppas N.A, (1989) Correlation between mesh size and equilibrium degree of swelling of polymeric networks, J. Biomed. Mater. Res., 23, 1183-1193. https://doi.org/10.1002/jbm.820231007

[44]. Betz M, Hörmansperger J, Fuchs T, Kulozik U, (2012) Swelling behaviour, charge and mesh size of thermal protein hydrogels as influenced by $p H$ during gelation, Soft Matter, 8, 2477. http://dx.doi.org/10.1039/C2SM06976H

[45]. Kirchhof S, Abrami M, Messmann V, et al., (2015) Diels-Alder Hydrogels for Controlled Antibody Release: Correlation between Mesh Size and Release Rate Mol. Pharmaceutics, 12 (9), 3358-3368. https://doi.org/10.1021/acs.molpharmaceut.5b00375

[46]. Coelho J.F.J., Gonçalves, P.M.O.F, Gil M. H. (2005) unpublished work 
[47]. Coelho J.F.J, et al., (2009) Synthesis of poly(2-methoxyethyl acrylate) by single electron transferDegenerative transfer living radical polymerization catalyzed by $\mathrm{Na}_{2} \mathrm{~S}_{2} \mathrm{O}_{4}$ in water, Journal of Polymer Science: Part A: Polymer Chemistry, 47, 4454-4463. https://doi.org/10.1002/pola.23548 